\title{
Correlation of Cytochrome P450 (CYP) IA2 Activity Using Caffeine Phenotyping and Olanzapine Disposition in Healthy Volunteers
}

\author{
Kara Lee Shirley', Yuen Y Hon ${ }^{2}$, Scott R Penzak ${ }^{3}$, YW Francis Lam ${ }^{4}$, Vicky Spratlin² and Michael W Jann*,2 \\ 'Albany College of Pharmacy, Albany, NY, USA; ${ }^{2}$ Mercer University Southern School of Pharmacy, Atlanta, GA, USA; ${ }^{3}$ National Institutes of Health \\ Clinical Center Pharmacy Department, Bethesda, MD, USA; ${ }^{4}$ University of Texas Health Science Center at San Antonio, San Antonio, TX, USA
}

\begin{abstract}
Olanzapine has previously been shown to have predominant metabolism by cytochrome (CYP) P450 IA2. Caffeine has been shown to provide an accurate phenotypic probe for measuring CYPIA2 activity. The purpose of this study is to determine if a significant correlation exists between olanzapine disposition and caffeine metabolic ratios. Subjects were phenotyped for CYPIA2 activity with caffeine probe methodology. After 200-mg caffeine administration, blood (4h), saliva (6 and 10 h), and urine ( $8 \mathrm{~h}$ total) were collected for highperformance liquid chromatography (HPLC) analysis of caffeine and its metabolites.CYPIA2 activity was measured as plasma (PMR $4 \mathrm{~h})$, saliva $\left(\mathrm{SMR}_{6 \mathrm{~h}}\right.$ and $\left.\mathrm{SMR}_{10 \mathrm{~h}}\right)$, and three urinary metabolic $\left(\mathrm{UMR} \mathrm{I}_{8 \mathrm{~h}}, \mathrm{UMR} 2_{8 \mathrm{~h}}\right.$, and $\left.\mathrm{UMR} 3_{8 \mathrm{~h}}\right)$ ratios. Each of the 14 healthy nonsmokers ( 13 male) received a single $10 \mathrm{mg}$ olanzapine dose after which blood was collected for HPLC determination of olanzapine concentrations at predose and at $0.5,1,1.5,2,2.5,3,4,5,6,8,10,12,24,48,72,96$, and $120 \mathrm{~h}$ postdose. Olanzapine pharmacokinetic parameters in this study were similar to those previously published. All caffeine metabolic ratios $\left(\mathrm{PMR}_{4 \mathrm{~h}}, \mathrm{SMR}_{6 \mathrm{~h}}, \mathrm{SMR}_{10 \mathrm{~h}}, \mathrm{UMRI}_{8 \mathrm{~h}}, \mathrm{and}_{\mathrm{U}} \mathrm{UMR} 2_{8 \mathrm{~h}}\right)$ significantly correlated with each other $(p<0.00 \mathrm{I})$ except for $U M R 3_{8} \mathrm{~h}$, which did not correlate. A significant correlation $(p<0.05)$ was also found between olanzapine clearance and PMR $4 \mathrm{~h}(r=0.70 \mathrm{I}), \mathrm{SMR}_{6 \mathrm{~h}}(r=0.644), \mathrm{SMR}_{10 \mathrm{~h}}(r=0.70 \mathrm{I}), \mathrm{UMRI} 8 \mathrm{~h}(r=0.745)$, and $\mathrm{UMR}_{8 \mathrm{~h}}(r=0.7 \mathrm{l0})$. A negative correlation was observed between olanzapine clearance and UMR3 $8 \mathrm{~h}(r=-0.029, p=\mathrm{NS})$. A significant correlation was found between olanzapine clearance and various caffeine metabolic ratios. Interpatient variability in CYPIA2 activity may explain the wide interpatient variability in olanzapine disposition. Compounds that modulate CYPIA2 activity may be expected to alter olanzapine pharmacokinetics accordingly.

Neuropsychopharmacology (2003) 28, 96 I-966, advance online publication, 19 March 2003; doi:I 0.1038/sj.npp. I 300 I 23
\end{abstract}

Keywords: olanzapine; CYPIA2; pharmacokinetics; caffeine

\section{INTRODUCTION}

Caffeine (1,3,7-trimethylxanthine [137X]) is one of the most commonly ingested compounds throughout the world. The metabolic pathways of caffeine are complex but involve the formation of three principal metabolites: theobromine (3,7dimethyl xanthine [37X]), theophylline (1,3-dimethylxanthine [13X]), and paraxanthine (1,7-dimethylxanthine $[17 \mathrm{X}])$. Each of these metabolites are primarily formed by cytochrome (CYP) P450 1A2 (Carrillo et al, 2000). Conversion to the $17 \mathrm{X}$ metabolite comprises about $80 \%$ of the metabolic pathway for caffeine. The metabolic pathways to

Primary Source of Funding: This project was partially supported by Eli Lilly.

*Correspondence: Dr MW Jann, Department of Clinical and Administrative Sciences, Southern School of Pharmacy, Mercer University, 300 I Mercer University, Atlanta, GA 3034I, USA, Tel: + I 678547 6342, Fax: + 678547 6190, E-mail: jann_mw@mercer.edu Received 17 July 2002; revised 14 November 2002; accepted 26 November 2002

Online publication: 4 December 2002 at http://www.acnp.org/ Citations/Npp I 20402439 the 37X and 13X metabolites are also influenced by CYP2E1 (Sinues et al, 1999). Caffeine has become popular as a metabolic probe for CYP1A2 activity in humans (Carrillo et $a l, 2000)$; it is one of the major P450 cytochromes in the liver and accounts for $15 \%$ of the total P450 content.

In addition to caffeine, clinically important psychotropic medications such as olanzapine, clozapine, haloperidol, thioridazine, imipramine, clomipramine, fluvoxamine, and tacrine are completely or partially metabolized by this enzyme (Carrillo et al, 2000; Callaghan et al, 1999; Bertilsson et al, 1994; Spigset et al, 1999a; Otani and Aoshima, 2000). Thus, interindividual variability in CYP1A2 activity may alter the pharmacokinetics of these medications and influence response to therapy, including toxicities such as tardive dyskinesia with older (typical) antipsychotics (Carrillo et al, 2000; Kelly et al, 1999; Basile et al, 2000; Ou-Yang et al, 2000).

Olanzapine is an atypical antipsychotic agent used in the treatment of schizophrenia, bipolar disorders, and other psychotic conditions. Olanzapine is metabolized to 10 - and $4^{\prime}$-N-glucuronide, $4^{\prime}$ - $N$-desmethylolanzapine via CYP1A2, and olanzapine $N$-oxide by flavin monooxygenase 
(Callaghan et al, 1999). Conversion to the 2-hydroxymethylolanzapine by CYP2D6 is a minor pathway for olanzapine (Ring et al, 1995). Clozapine, like olanzapine, is metabolized by a variety of CYP isozymes including CYP1A2, CYP3A4, CYP2D6 and the flavin monooxygenase (Jann et al, 1993; Otani and Aoshima, 2000). Clozapine disposition was found to covary with CYP1A2 activity in 14 healthy volunteers, where the reciprocal of clozapine's area under the plasma concentration-time curve (AUC) significantly correlated with urinary caffeine $N$-3 demethylation index or its conversion to $17 \mathrm{X}$ metabolite $(r=0.84, p<0.0024)$. Clozapine clearance was also found to correlate significantly with the other caffeine 37X and 13X indexes $(r=0.89, p<0.0013$; and $r=0.85, p<0.0023$ ) (Bertilsson et al, 1994). Olanzapine disposition was evaluated in seventeen healthy volunteers where concentrations of caffeine and $17 \mathrm{X}$ were measured in saliva $10 \mathrm{~h}$ postcaffeine dosing (Hagg et al, 2001). A significant correlation between caffeine activity (caffeine/ $17 \mathrm{X}$ ratio) and olanzapine clearance was not found $(r=0.19$, $p=0.56$ ). However, each of these studies used only one biological matrix to assess caffeine metabolism (such as only urine or saliva concentrations).

The purpose of this study was to examine the relation between olanzapine disposition and CYP1A2 activity as determined by caffeine phenotyping with plasma, saliva and urine concentrations of caffeine, and its $17 \mathrm{X}$ and $13 \mathrm{X}$ metabolites.

\section{METHODS}

\section{Subjects}

The Mercer University Institutional Review Board approved this study and each participant provided written informed consent. In all, 15 healthy nonsmokers (14 male, one female) participated in this study. Subjects were included in our investigation if they met the following inclusion criteria: medically healthy volunteers, men and women over 18 years of age, women of childbearing potential on medically acceptable birth control excluding oral contraceptives, hormonal implants, or depo-injections. Subjects were also excluded if they met any of the following exclusion criteria: presence of any chronic medical condition, pregnancy and/ or breastfeeding, history of alcohol, tobacco or drug abuse, use of any prescription or over-the counter medications or herbal remedies metabolized by the CYP P450 1A2 system, or an inability to comply with a diet free of caffeine, ethanol, and grapefruit juice and products $48 \mathrm{~h}$ before the overnight stay prior to the study day. The health status of our subjects was assessed by a thorough health and medication history, physical examination, and a complete metabolic and hematologic blood profile, prior to study protocol initiation.

\section{Study Design}

Subjects were asked to comply with a diet free of caffeine, ethanol, and grapefruit juice/products for $48 \mathrm{~h}$, and come to the Center for Clinical Research (CCR) for an overnight stay of approximately $12 \mathrm{~h}$ prior to the initiation of the study day. The investigator confirmed compliance with the protocol-specified diet via detailed subject interviews. After eating a standardized breakfast, subjects received $200 \mathrm{mg}$ of caffeine (No-Doz $\left.{ }^{\circledR}\right)$. Previously standardized procedures were used for obtaining plasma; saliva and urine samples were established by previous investigators (Carrillo et al, 2000; Spigset, 1999b). Each subject had two $10 \mathrm{ml}$ blood samples drawn; one sample was obtained prior to caffeine administration and the second sample $4 \mathrm{~h}$ postcaffeine dosing. All samples were collected in EDTA vacutainer tubes and centrifuged at $3200 \mathrm{~g}$ for $10 \mathrm{~min}$ after which plasma was harvested and stored at $-80^{\circ} \mathrm{C}$ until it was analyzed for caffeine and paraxanthine.

Immediately after caffeine administration, subjects began to collect their urine and continued to do so over the next $8 \mathrm{~h}$. All urine samples were measured individually for total volume and then aliqoted into smaller samples, which were subsequently acidified to a $\mathrm{pH}$ of 4.0 with $0.1 \mathrm{M}$ hydrochloric acid before storage at $-80^{\circ} \mathrm{C}$ (preservation of caffeine metabolites). At 6 and $10 \mathrm{~h}$ after caffeine administration subjects were asked to chew on a piece of paraffin wax film to stimulate saliva production and a $2 \mathrm{ml}$ sample of saliva was collected and stored at $-80^{\circ} \mathrm{C}$ until the time of analysis.

Each of the 14 subjects received a single $10 \mathrm{mg}$ olanzapine dose. Venous blood samples were collected for highperformance liquid chromatography (HPLC) determination of olanzapine concentrations at predose and at $0.5,1,1.5,2$, $2.5,3,4,5,6,8,10,12,24,48,72,96$, and $120 \mathrm{~h}$ postdose. All samples were stored at $-80^{\circ} \mathrm{C}$ until assayed. One male subject withdrew from the study for personal reasons and did not participate in olanzapine dosing.

\section{Analytic Methods}

Olanzapine plasma concentrations were assayed by Bioanalytical Services (BAS; west Lafayette, IN) by a published HPLC method developed by the drug's manufacturer (Eli Lilly Pharmaceuticals, Indianapolis, IN) by HPLC (Catlow et al, 1995). Plasma, urine and salivary caffeine (137X) metabolites (17X, 13X, 5-acetylamino-6-amino-3-methyluracil (AAMU), 1-methylxanthine (1X), 1-methyl uric acid $(1 \mathrm{U})$, and 1,7 dimethyl uric acid (17U) were analyzed using validated HPLC methodology (El-Yazigi et al, 1999; Fuhr and Rost, 1994). CYP1A2 activity was measured as plasma (PMR), salivary (SMR), and urinary metabolite (UMR) to caffeine metabolic ratios were validated in previous phenotypic studies (Fuhr et al, 1996; Spigset et al, 1999; Carrillo et al, 2000).

\section{Data and Statistical Analysis}

Olanzapine pharmacokinetic parameters values for each subject were determined with the use of noncompartmental methods and are displayed in Table 1. Maximal plasma concentrations $\left(C_{\max }\right)$ and time to reach $C_{\max }\left(T_{\max }\right)$ were determined by visual inspection of the concentration-time profiles. The elimination rate constant $\left(\lambda_{z}\right)$ was estimated as the absolute value of the slope of a linear regression of natural logarithm of concentration $v s$ time. Half-life was calculated as $\ln 2 / \lambda_{z}$. The area under the plasma concentration-time curve $\left(\mathrm{AUC}_{0-\infty}\right)$ was determined by the linear trapezoidal rule with extrapolation to infinity $\left(\mathrm{AUC}_{0-\infty}\right)$ by dividing the last concentration measured by the elimination rate constant $\left(\lambda_{z}\right)$. Oral clearance $(\mathrm{CL} / \mathrm{F})$ was determined by dividing the dose administered by $\mathrm{AUC}_{0-\infty}$ and the 
Table I Olanzapine Single-Dose Pharmacokinetics and Caffeine $\mathrm{PMR}_{4 \mathrm{~h}}$ are Presented $(\mathrm{N}=14)$

\begin{tabular}{|c|c|c|c|c|c|c|}
\hline Subject & $\begin{array}{l}\text { AUC }_{0 \rightarrow \infty} \\
(\mathrm{ng} \mathrm{h} / \mathrm{ml})\end{array}$ & $\begin{array}{l}\text { CL/F } \\
(\mathbf{I} / \mathbf{h})\end{array}$ & $\begin{array}{c}T_{1 / 2} \\
\text { (h) }\end{array}$ & $\underset{(\mathrm{ng} / \mathrm{ml})}{C_{\max }}$ & $\begin{array}{c}T_{\max } \\
\text { (h) }\end{array}$ & $\mathrm{PMR}_{4 \mathrm{~h}}$ \\
\hline I & 541 & 18.5 & 24 & 17 & 3 & 0.342 \\
\hline 2 & 833 & 12 & 29 & 25 & 10 & 0.129 \\
\hline 3 & 520 & 19.2 & 50 & 19 & 2 & 0.161 \\
\hline 4 & 449 & 22.3 & 30 & 10 & 10 & 0.648 \\
\hline 5 & 481 & 20.8 & 32 & 22 & 3 & 0.590 \\
\hline 6 & 430 & 23.3 & 25 & 20 & 2 & 0.717 \\
\hline 7 & 431 & 23.2 & 27 & 12 & 10 & 0.483 \\
\hline 8 & 565 & 17.7 & 31 & 18 & 4 & 0.390 \\
\hline 9 & 441 & 22.7 & 29 & 12 & 2 & 0.522 \\
\hline 10 & 672 & 14.9 & 36 & 12 & 10 & 0.267 \\
\hline II & 369 & 27.1 & 27 & 17 & 3 & 0.589 \\
\hline 12 & 539 & 18.6 & 30 & 13 & 6 & 0.292 \\
\hline 13 & 399 & 25.1 & 45 & 13 & 2 & 0.296 \\
\hline 14 & 508 & 19.7 & 36 & 12 & 3 & 0.311 \\
\hline Mean & 501 & 20 & 32 & 15 & 4 & 0.410 \\
\hline $\mathrm{Cl}$ & $443-582$ & $18-23$ & $28-36$ & $13-19$ & $3-7$ & $0.312-0.508$ \\
\hline
\end{tabular}

$\mathrm{AUC}_{0 \rightarrow \infty}$, AUC from time zero to infinity; CL/F, oral clearance; $T_{1 / 2}$, half-life; $C_{\max }$, maximum concentration; $T_{\max }$, time to maximum concentration; $V_{d}$, apparent volume of distribution. Mean, geometric mean; Cl, 95\% confidence intervals.

apparent volume of distribution (V/F) was calculated as the ratio of $\mathrm{CL} / \mathrm{F}$ to $\lambda_{z}$. The $95 \%$ confidence intervals (CIs) for the differences in means for the log-transformed pharmacokinetic parameter values were transformed back to the original scale to give $95 \%$ CIs for the geometric means.

CYP1A2 activity was determined as molar ratios (MRs) of caffeine metabolites in plasma $(\mathrm{P})$ at $4 \mathrm{~h}\left(\mathrm{PMR}_{4 \mathrm{~h}}\right)$ calculated as $17 \mathrm{X} / 137 \mathrm{X}$, and saliva $(\mathrm{S})$ at 6 and $10 \mathrm{~h}\left(\mathrm{SMR}_{6 \mathrm{~h}}\right.$ and $\mathrm{SMR}_{10 \mathrm{~h}}$ ) calculated as $17 \mathrm{X} / 137 \mathrm{X}$. The urinary $(\mathrm{U}) \mathrm{MR}$ at $8 \mathrm{~h}$ $\left(\mathrm{UMR}_{8 \mathrm{~h}}\right)$ were determined in three different calculations with different metabolite concentrations: $\mathrm{UMR} 1_{8 \mathrm{~h}}=17 \mathrm{X} /$ $137 \mathrm{X} ; \mathrm{UMR} 2_{8 \mathrm{~h}}=17 \mathrm{X}+17 \mathrm{U} / 137 \mathrm{X}$; and $\mathrm{UMR} 3_{8 \mathrm{~h}}=\mathrm{AAMU}+$ 1X + 1U/17U (Fuhr et al, 1996; Spigset et al, 1999; Carrillo et al, 2000). Olanzapine clearance data and caffeine metabolic ratios were tested for normality with ShapiroWilk tests. Olanzapine clearance covariation with CYP1A2 activity $\mathrm{PMR}_{4 \mathrm{~h}}, \mathrm{SMR}_{6 \mathrm{~h}}, \mathrm{SMR}_{10 \mathrm{~h}}, \mathrm{UMR} 1_{8 \mathrm{~h}}, \mathrm{UMR} 2_{8 \mathrm{~h}}$, and $\mathrm{UMR}_{8 \mathrm{~h}}$ was tested with Pearson's correlation coefficient. Statistical significance is defined as $p<0.05$ and calculations were performed with Statistica $6.0{ }^{\mathbb{R}}$.

\section{RESULTS}

The 14 subjects ( 13 men and one woman) were between 20 and 28 years old (mean, $25 \pm 2.9$ years). A wide intersubject variability was found with olanzapine pharmacokinetic parameters shown in Table 1. No concomitant medications were taken by any of the study participants. In general, the study medications were adequately tolerated. All subjects experienced marked somnolence during the first day of the olanzapine pharmacokinetic evaluation. Sedation continued into the next day, but was much less pronounced. By the third day after olanzapine ingestion all subjects reported feeling 'normal' again.

CYP1A2 phenotype was analyzed in all 15 subjects. A wide range with three- to eight-fold differences of $\mathrm{PMR}_{4} \mathrm{~h}$,
$\mathrm{SMR}_{6 \mathrm{~h}}, \mathrm{SMR}_{10 \mathrm{~h}}, \mathrm{UMR}_{8 \mathrm{~h}}, \mathrm{UMR} 2_{8 \mathrm{~h}}$, and $\mathrm{UMR}_{8 \mathrm{~h}}$ ratios were observed in the subjects. A summary of the caffeine metabolite ratios is presented in Table 2. The $\mathrm{PMR}_{4 \mathrm{~h}}$, $\mathrm{SMR}_{6 \mathrm{~h}}, \mathrm{SMR}_{10 \mathrm{~h}} \mathrm{UMR} 1_{8 \mathrm{~h}}$, and $\mathrm{UMR} 2_{8 \mathrm{~h}}$ ratios were normally distributed as determined by the Shapiro-Wilk test, while the $\mathrm{UMR}_{8 \mathrm{~h}}$ ratio was not. The correlation between $\mathrm{PMR}_{4 \mathrm{~h}}, \mathrm{SMR}_{6 \mathrm{~h}}, \mathrm{SMR}_{10 \mathrm{~h}}, \mathrm{UMR} 1_{8 \mathrm{~h}}, \mathrm{UMR} 2_{8 \mathrm{~h}}$, and $\mathrm{UMR}_{8 \mathrm{~h}}$ ratios are shown in Table 3 . All caffeine metabolic

Table 2 Summary of Caffeine Metabolic Ratios ( $N=15)$

\begin{tabular}{lc}
\hline Parameter & Median (range) \\
\hline $\mathrm{PMR}_{4 h}$ & $0.402(0.129-0.717)$ \\
$\mathrm{SMR}_{6 \mathrm{~h}}$ & $0.614(0.186-0.899)$ \\
$\mathrm{SMR}_{10 \mathrm{~h}}$ & $0.892(0.307-1.37)$ \\
$\cup M R I_{8 h}$ & $2.21(0.664-5.36)$ \\
$\cup M R 2_{8 \mathrm{~h}}$ & $4.12(1.24-8.48)$ \\
$\mathrm{UMR}_{8 \mathrm{~h}}$ & $14.1(9.22-32.0)$ \\
\hline
\end{tabular}

Table 3 Correlation Matrix of Caffeine Metabolite Ratios $(N=15)$

\begin{tabular}{|c|c|c|c|c|c|}
\hline Parameter & $\mathbf{P M R}_{4 \mathrm{~h}}$ & $\mathbf{S M R}_{6 \mathrm{~h}}$ & $S M R_{10 h}$ & $U M R I_{8 h}$ & $\mathbf{U M R}_{\mathbf{8 h}}$ \\
\hline \multicolumn{6}{|l|}{$\mathrm{PMR}_{4 h}$} \\
\hline $\mathrm{SMR}_{6 \mathrm{~h}}$ & $0.87 \mid *$ & & & & \\
\hline $\mathrm{SMR}_{10 \mathrm{~h}}$ & $0.86 \mid *$ & $0.800 *$ & & & \\
\hline $\mathrm{UMRI}_{8 \mathrm{~h}}$ & $0.921 *$ & $0.882 *$ & $0.761^{*}$ & & \\
\hline$U M R 2_{8 h}$ & 0.925* & 0.896* & $0.77 \mid *$ & 0.968* & \\
\hline $\mathrm{UMR}_{8 \mathrm{~h}}$ & $(-) 0.321$ & $(-) 0.232$ & $(-) 0.079$ & $(-) 0.354$ & $(-) 0.379$ \\
\hline
\end{tabular}

* $p<0.001,(-)=$ negative correlation.

Table 4 Correlation Between Olanzapine Clearance (CL/F) and Various Caffeine Metabolite Ratios $(N=\mid 4)$

\begin{tabular}{lc}
\hline Parameter & Olanzapine (CL/F) \\
\hline $\mathrm{PMR}_{4 h}$ & $0.701^{*}$ \\
$\mathrm{SMR}_{6 \mathrm{~h}}$ & $0.644^{*}$ \\
$\mathrm{SMR}_{10 \mathrm{~h}}$ & $0.701^{*}$ \\
$\cup M R I_{8 \mathrm{~h}}$ & $0.745^{*}$ \\
$\cup M R 2_{8 \mathrm{~h}}$ & $0.710 *$ \\
$\mathrm{UMR}_{8 \mathrm{~h}}$ & $(-) 0.029$ \\
\hline
\end{tabular}

* $p<0.05 ;(-)=$ negative correlation.

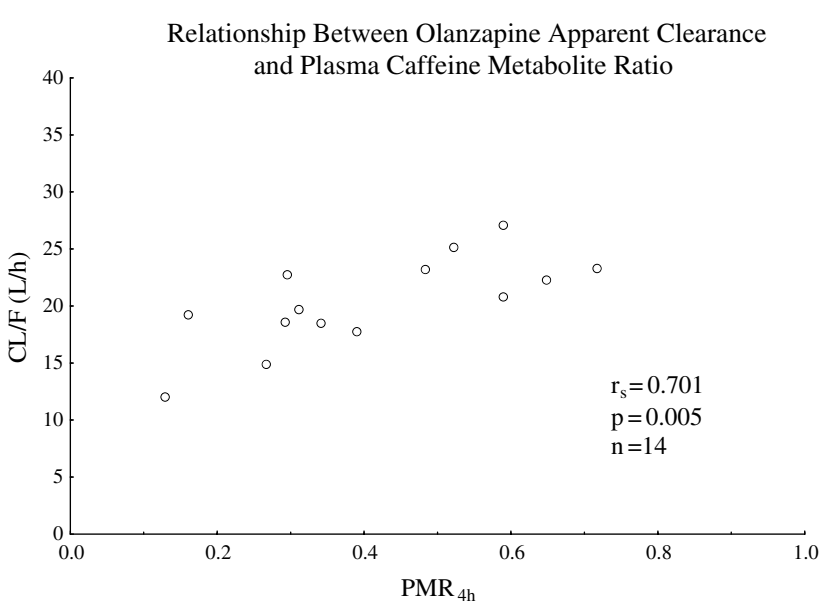

Figure I Relation between olanzapine apparent clearance and plasma caffeine metabolite ratio. 
ratios were significantly correlated to each other except for the UMR $3_{8 \mathrm{~h}}$ ratio.

The correlation between olanzapine clearance and caffeine metabolite ratios are presented in Table 4. In spite of the wide intersubject variability in $\mathrm{PMR}_{4 \mathrm{~h}}$ and olanzapine clearance (Figure 1; Table 1), these parameters were significantly correlated $(r=0.701, p<0.005)$ as were all caffeine metabolite ratios with olanzapine clearance except for UMR $3_{8 \mathrm{~h}}$.

\section{DISCUSSION}

Similar to previous pharmacokinetic studies conducted by others, our study showed a large intersubject variability in olanazpine disposition (Callaghan et al, 1999). Nonetheless, olanzapine pharmacokinetic parameters are similar between the investigations.

Olanzapine has previously been shown to be metabolized by CYP1A2. The other major olanzapine metabolic pathway involves the conversion to olanzapine $10-\mathrm{N}$-glucuronide via the uridine disphosphate glucuronyltransferase (UDPGT) enzyme system (Ring et al, 1995). To a minor extent, CYP2D6 and other metabolic enzymes convert olanzapine to its remaining metabolites such as 2-hydroxyolanzapine, olanzapine $\mathrm{N}$-oxide, and olanzapine $4^{\prime}-\mathrm{N}$-glucuronide (Callahan et al, 1999). Thus, CYP1A2 appears to play a major role in olanzapine disposition. For example, smoking - a wellknown inducer of CYP1A2 - contributed to a $40 \%$ higher olanzapine clearance among smokers compared to nonsmokers (Callahan et al, 1999). Since many psychiatric patients smoke, they should be cautioned that smoking cessation may result in elevated plasma concentrations of olanzapine; increased adverse effects, such as sedation, may result.

Gender is another factor that affects olanzapine disposition. Large population studies have found that women have a $25 \%$ lower olanzapine clearance compared to men (Callahan et al, 1999). A retrospective investigation examined differential olanzapine plasma concentrations by gender with a fixed-dose regimen (Kelly et al, 1999). Women volunteers in this study were found to have significantly higher plasma concentrations of olanzapine than men at five (5) weeks, even with a fixed dose administration. It was proposed that these differences in olanzapine pharmacokinetics were in part because of gender differences in CYP1A2 metabolism, with women having less CYP1A2 activity than men (Kelly et al, 1999).

Caffeine metabolism is complex but its biotransformation profile has been clearly determined. In addition to caffeine's metabolism previously described, conversion from paraxanthine $(17 \mathrm{X})$ to $1 \mathrm{U}$ via the $1 \mathrm{X}$ metabolite is mediated by CYP1A2 and xanthine oxidase. Paraxanthine (17X) is converted to an intermediate metabolite by CYP1A2, then to AFMU by $N$-acetyltransferase type 2 enzyme (NAT2), and finally to AAMU (Sinues et al, 1999). Paraxanthine is also converted to its $17 \mathrm{U}$ metabolite by demethylation and influenced by CYP1A2 and CYP2A6 (El-Yagiki et al, 1999). Several concentration ratios of caffeine and its metabolites in plasma, saliva, and urine have been proposed to assess CYP1A2 activity. Whereas plasma and saliva paraxanthine to caffeine ratios have been shown to correlate closely to intrinsic clearance of caffeine 3-demethylation and CYP1A2 content (Fuhr et al, 1996), optimal sampling for phenotype analysis is suggested to be 3-6 h after caffeine intake for serum and 6-10 h after caffeine intake for saliva (Spigset et al, 1999). The time periods in which plasma and saliva were collected for this study were comparable with those of Spigset, and the caffeine metabolite ratios are very similar to those of previous studies (Table 2) (Fuhr et al, 1996; Spigset et al, 1999).

Unlike plasma and saliva samples, adequate urine collection interval for the measurement of CYP1A2 activity has not been established. Previous studies used urine samples collected from 4 to $5 \mathrm{~h}$ (Chung et al, 2000; Lampe et al, 2000; Sinues et al, 1999) or 0 to $24 \mathrm{~h}$ (Bertilsson $e t$ al, 1994; Sinues et al, 1999) after caffeine intake to assess CYP1A2 activity. We collected urine from 0 to $8 \mathrm{~h}$ in this study to minimize the effects of urine flow rate on excretion of different metabolites and also to make the sample collection easier. The results that we obtained are different from those of previous studies; however, a direct comparsion of results from our study and others is difficult because of different urine collection schedules.

The correlation matrix for caffeine metabolic ratios shown in Table 3 displays significant relations between plasma, saliva and urinary ratios except for UMR $3_{8 \mathrm{~h}}$. These findings are consistent with previous results that plasma ratios significantly correlated with saliva ratios at 3 and $6 \mathrm{~h}$ postdose (Fuhr et al, 1996). The urinary metabolite ratio UMR $1_{0-8 \mathrm{~h}}$ and UMR $2_{0-8 \mathrm{~h}}$ in this study significantly correlated with plasma and saliva ratios, and olanzapine apparent clearance, indicating that these ratios can also be used as a reliable marker for CYP1A2 activity in addition to plasma and saliva ratios. A possible explanation for the lack of significant correlation for $\mathrm{UMR}_{8 \mathrm{~h}}$ ratio and the other caffeine metabolite ratios is that the metabolic pathways for these metabolites (AAMU and 1U) are also influenced by other enzymes (NAT2 and xanthine oxidase), thereby increasing the variability of metabolite concentrations.

Previously, clozapine clearance was shown to correlate significantly with caffeine disposition, indicating a significant relation between clozapine clearance and CYP1A2 activity (Bertilsson et al, 1994). Clozapine clearance was found to be significantly correlated with the $17 \mathrm{X} / 137 \mathrm{X} \quad(r=0.89$, $p<0.0013)$ and the $37 \mathrm{X} / 137 \mathrm{X}$ ratio $(r=0.85, p<0.0023)$. Very high CYP1A2 activity as indicated by a urinary caffeine metabolic ratio of 17.9 (usual range 1.9-1.47) was reported in one patient; excessive CYP1A2 activity in this patient was associated with a subtherapeutic clozapine plasma concentration of $661 \mathrm{nmol} / \mathrm{l}$ (minimum threshold $1150 \mathrm{nmol} /$ $1=350 \mathrm{ng} / \mathrm{ml}$ ), despite a drug dose of $850 \mathrm{mg} /$ day (Ozdemir et al, 2001a). Fluvoxamine $25 \mathrm{mg} /$ day, a well-known CYP1A2 inhibitor, was added to the patient's regimen and a subsequent clozapine plasma concentration of $1600 \mathrm{nmol} / \mathrm{l}$ was reached and the patient's clinical status improved. A repeat urinary caffeine ratio was conducted and it was reduced to 9.1 during fluvoxamine coadmininistration indicating a reduction in CYP1A2 activity with the addition of this agent. Like clozapine, a minimum therapeutic threshold for olanzapine plasma concentrations was identified and found to be $9.3 \mathrm{ng} / \mathrm{ml}$ (Perry et al, 1997, 2001). It is possible that a very high CYP1A2 activity could reduce olanzapine concentrations and influence a patient's response to the drug. Conversely, patients with low CYP1A2 activity could experience adverse side effects at low to moderate 
olanzapine doses because of increased olanzapine exposure. Caffeine phenotyping - a relatively inexpensive and available analytical procedure - could provide an explanation for these clinical situations.

In a recent study, olanzapine clearance did not significantly correlate with CYP1A2 activity when SMR's $s_{10 \mathrm{~h}}$ were compared (Hagg et al, 2001). Subjects in that study were also phenotyped for CYP2D6 status with 12 patients identified as EM's and 5 as PM's; however, this differientation had no impact upon CYP1A2 activity and olanzapine clearance. Our findings, where $\mathrm{SMR}_{6 \mathrm{~h}}$ and $\mathrm{SMR}_{10 \mathrm{~h}}$ caffeine ratios correlated with olanzapine clearance, are not in agreement with these results. In fact, all other caffeine metabolic ratios except $\mathrm{UMR}_{8 \mathrm{~h}}$ in our study were found to correlate significantly with olanzapine clearance (Table 4). A possible explanation for disparity between the studies is unclear and warrants further investigation. It was reported that the $\mathrm{N}$-desmethylolanzapine metabolic ratio significantly correlated with olanzapine clearance $\left(r^{2}=0.35, p<0.0002\right)$ in large population studies (Callahan et al, 1999). This major metabolic pathway for olanzapine is mediated by CYP1A2. Although our study does not extend any ground-breaking new knowledge regarding olanzapine metabolism and CYP1A2, it does confirm the use of caffeine as a phenotypic probe for olanzapine disposition and explains the large intersubject variability found with olanzapine metabolism. Similar results with clozapine and desmethylclozapine metabolite plasma concentrations were found in schizophrenic patients at steady-state conditions (Ozdemir et al, 2001b). A significant correlation was reported between clozapine and desmethylclozapine $(r=0.86, p<0.01)$. A significant but negative correlation between desmethylclozapine plasma concentrations and urinary caffeine metabolic ratios were found $(r=(-) 0.76, p<0.01)$, indicating that its formation is influenced by CYP1A2.

Limitations to our study include the fact that only one female participated; thus gender influences on olanzapine disposition could not be evaluated. Also, our study did not include phenotyping for CYP2D6 status among the study subjects. Since this is a minor metabolic pathway for olanzapine, the contribution of this information would be minimal and difficult to justify additional study procedures.

\section{CONCLUSIONS}

Our study indicates that olanzapine disposition is significantly correlated with CYP1A2 activity as measured by caffeine $\mathrm{PMR}_{4 \mathrm{~h}}, \mathrm{SMR}_{6 \mathrm{~h}}, \mathrm{SMR}_{10 \mathrm{~h}}, \mathrm{UMR} 1_{8 \mathrm{~h}}$, and UMR $2_{8 \mathrm{~h}}$ metabolic ratios. Further studies are needed to compare the influence of gender and smoking upon olanzapine clearance and caffeine metabolic ratios.

\section{REFERENCES}

Basile VS, Ozdemir V, Masellis M, Meltzer HY, Lieberman JA, Potkin SG et al (2000). A functional polymorphism of the cytochrome P450 1A2 (CYP1A2) gene: association with tardive dyskinesia in schizophrenia. Mol Psychiatry 5: 410-417.

Bertilsson L, Carrillo JA, Dahl ML, Llerena A, Alm C, Bondesson U et al (1994). Clozapine disposition covaries with CYP1A2 activity determined by a caffeine test. Br J Pharmacol 38: 471-473.
Callaghan JT, Bergstrom RF, Ptak LR. (1999). Olanzapine: pharmacokinetic and pharmacodynamic profile. Clin Pharmacokin 37: 177-193.

Carrillo JA, Christensen M, Ramos S, Alm C, Dahl ML, Benitez J et al (2000). Evaluation of caffeine as an in vivo probe for CYP 1A2 using measurements in plasma, saliva and urine. Ther Drug Monit 22: 409-417.

Catlow JT, Barton RD, Clemens M, Gillespie TA, Goodwin M, Swanson SP. (1995). Analysis of olanzapine in human plasma utilizing reversed-phase high performance liquid chromatography with electrochemical detection. J Chromatogr B 668: 85-90.

Chung WG, Kang JH, Park CS, Cho MH, Cha YN (2000). Effect of age and smoking on in vivo CYP1A2, flavin-containing monooxygenase, and xanthine oxidase activities in Koreans: determination by caffeine metabolism. Clin Pharmacol Ther 67: 258-266.

El-Yazigi A, Shabib S, Al-Rawithi S, Yusuf A, Legayada ES, Al-Humidan A. (1999). Salivary clearance and urinary metabolic pattern of caffeine in healthy children in pediatric patients with hepatocellular disease. J Clin Pharmacol 39: 366-372.

Fuhr U, Rost KL (1994). Simple and reliable CYP1A2 phenotyping by the paraxanthine/caffeine ratio in plasma and in saliva. Pharmacogenetics 4: 109-116.

Fuhr U, Rost KL, Engelhardt R, Sachs M, Liermann D, Belloc C et al (1996). Evaluation of caffeine as a test drug for CYP1A2, NAT2 and CYP2E1 phenotyping in man by in vivo versus in vitro correlations. Pharmacogenetics 6: 159-176.

Hagg S, Spigest O, Lakso HA, Dahlqvist R. (2001). Olanzapine disposition in humans is unrelated to CYP1A2 and CYP2D6 phenotypes. Eur J Clin Pharmacol 57: 493-497.

Jann MW, Grimsley SR, Gray EC, Chang WH (1993). Pharmacokinetics and pharmacodynamics of clozapine. Clin Pharmacokinet 24: 161-176.

Kelly DL, Conley RR, Tamminga CA. (1999). Differential olanzapine concentrations by sex in a fixed-dose study. Schizophr Res 40: 101-104.

Lampe JW, King IB, Li S, Grate MT, Barale KV, Chen C et al (2000). Brassica vegetables increase and apiaceous vegetables decrease cytochrome P450 IA2 activity in humans: changes in caffeine metabolite ratios in response to controlled vegetable diets Carcinogenesis 21: 1157-1162.

Otani K, Aoshima T (2000). Pharmacogenetics of classical and new antipsychotic drugs. Ther Drug Monit 22: 118-121.

Ou-Yang DS, Huang SL, Wang W, Xie HG, Xu ZH, Shu Y et al (2000). Phenotypic polymorphism and gender-related differences of CYP $1 \mathrm{~A} 2$ activity in a Chinese population. $\mathrm{Br} \mathrm{J}$ Pharmacol 49: 145-151.

Ozdemir V, Kalow W, Okey AB, Lam MSM, Albers L J, Reist C et al (2001a). Treatment resistant to clozapine in association with ultrarapid CYP1A2 activity and the c-A polymorphism in intron 1 of the CYP1A2 gene: effect of grapefruit juice and low-dose fluvoxamine. J Clin Psychopharmacol 21: 603-607.

Ozdemir V, Kalow W, Posner P, Collins EJ, Kennedy JL, Tang BK et al (2001b). CYP1A2 activity as measured by a caffeine test predicts clozapine and active metabolite norclozapine steadystate concentrations in patients with schizophrenia. J Clin Psychopharmacol 21: 398-407.

Perry PJ, Lund BC, Sanger T, Beasley C (2001). Olanzapine plasma concentrations and clinical response: acute phase results of the North American olanzapine trial. J Clin Psychopharmacol 21: 14-20.

Perry PJ, Sanger T, Beasley C (1997). Olanzapine plasma concentrations and clinical response in acutely ill schizophrenic patients. J Clin Psychopharmacol 17: 472-477.

Ring BJ, Catlow J, Lindsay TJ, Gillespie T, Roskos LK, Cermiele BJ et al (1995). Identification of the human cytochromes responsible for the in vitro formation of the major oxidative metabolites of the antipsychotic agent olanzapine. J Pharmacol Exp Ther 276: 658-666. 
Sinues B, Saenz MA, Lanuza J et al (1999). Five caffeine metabolite ratios to measure tobacco-induced CYP1A2 activity and their relationships with urinary mutagenicity and urine flow. Cancer Epidemol Biomark Prevent 8: 159-166.

Spigset O, Hagg S, Soderstrom E, Dahlqvist R (1999a). Lack of correlation between fluvoxamine clearance and CYP 1A2 activity

as measured by systemic caffeine clearance. Eur J Clin Pharmacol 54: 943-946.

Spigset O, Hagg S, Soderstrom E, Dahlqvist R (1999b). The paraxanthine: caffeine ratio in serum or saliva as a measure of CYP 1A2 activity: when should the sample be obtained? Pharmacogenetics 9: 409-412. 